\title{
Fisiopatología de la hipertensión arterial
}

\section{Pathophysiology of arterial hypertension}

\author{
Patrick Wagner-Grau ${ }^{1}$ \\ ${ }^{1}$ Presidente, Sociedad Peruana de Hipertensión Arterial.
}

\section{Resumen}

Diversos factores están implicados en la fisiopatología de la hipertensión arterial esencial. El elemento básico es la disfunción endotelial y la ruptura del equilibrio entre los factores vasoconstrictores y los vasodilatadores. Contribuyen a lo anterior, de modo importante, diversos factores hormonales, como el sistema captación y descarboxilación de los precursores de grupos amino (APUD) digestivo y el síndrome anémico.

Palabras clave: Hipertensión, fisiopatología; sistema renina angiotensina; hidrolasas diester fosforicas; anemia.

\begin{abstract}
Several factors are implicated in the pathophysiology of essential hypertension. The basic element is endothelial dysfunction and imbalance between vasoconstrictor and vasodilator factors. Various hormonal factors contribute importantly to this, such as the digestive amine precursor uptake decarboxylase (APUD) system and certain enzymes contributing to the anemic syndrome.

Keywords: Hypertension, pathophysiology; renin angiotensin system; phosphoric diester hydrolases; anemia.
\end{abstract}

An Fac med. 2010;71 (4):225-9
La hipertensión arterial (HTA) se caracteriza básicamente por la existencia de una disfunción endotelial (DE), con ruptura del equilibrio entre los factores relajantes del vaso sanguíneo (óxido nítrico -NO-, factor hiperpolarizante del endotelio -EDHF) y los factores vasoconstrictores (principalmente endotelinas). Es conocida la disminución a nivel del endotelio de la prostaciclina-PGI2 vasodepresora y el aumento relativo del tromboxano-TXA2 intracelular vasoconstrictor $^{(1)}$.

Revisaremos algunos de los principales factores.

\section{ENDOTELINAS}

Las endotelinas (ETs) son factores vasoconstrictores locales muy potentes, cerca de 10 a 100 veces más poderosos que la angiotensina II (2). Se sabe actualmente que se trata de un sistema complejo: pre-proendotelina $\Rightarrow$ proendotelina $\Rightarrow$ ET1. A nivel de la proendotelina actúa una enzima convertidora de la endotelina (ECE), formándose principalmente ET1, pero también en menor proporción, ET2 y ET3 ${ }^{(3)}$. Solo la ET1 parece poseer acción vasoconstrictora sistémica.

La ET1 ejerce diversas acciones: sobre el tono vascular ${ }^{(4)}$, la excreción renal de sodio y agua ${ }^{(5)}$ y la producción de la matriz extracelular ${ }^{(6)}$. Se ha descrito disfunción del sistema ET1 en estados de proteinuria crónica, en la acumulación de matriz extracelular glomerular e intersticial, así como en la nefropatía diabética, en la glomerulopatía hipertensiva y en otros tipos de glomerulonefritis ${ }^{(7,8)}$.

El endotelio es la principal fuente de ET1, pero no es la única. ET1 es sinterizada por las células epiteliales, las células musculares lisas vasculares, los macrófagos y en el seno de numerosos tejidos en los que se liga a sus receptores para ejercer su efecto. Sus dos receptores específicos, ETA y ETB, son capaces de iniciar efectos biológicos sinérgicos o diferentes, en el seno de una misma célula o entre tipos celulares distintos.

La concentración extracelular local de ET1 es regulada en su mayor parte por su internalización, y su aclaramiento por el receptor ETB endotelial ${ }^{(8-11)}$, así como

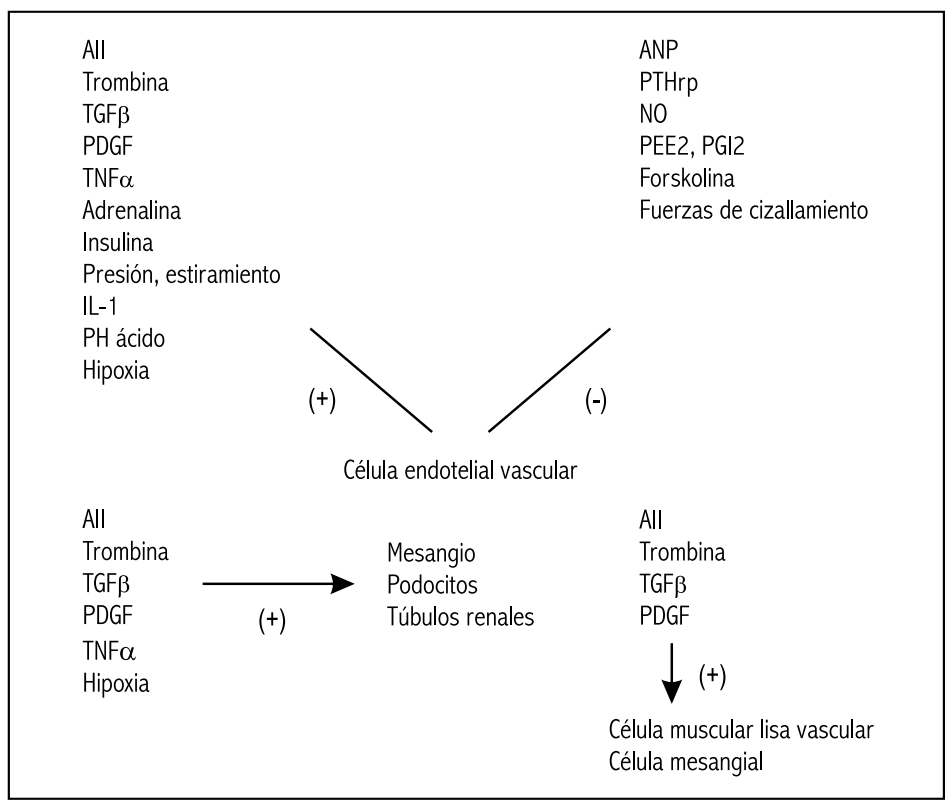

Figura 1. Factores estimuladores $(+)$ e inhibidores (-) de la síntesis de endotelina 1. 
por su secreción mayormente abluminal, hacen que ella (la ET1) actúe principalmente de manera autocrina o paracrina, permitiendo efectos confinados al microambiente local. Una gran variedad de factores modula su expresión, incluyendo la localización de las enzimas de su vía de biosíntesis, diversos agentes vasoactivos, citoquinas, factores de crecimiento o varias sustancias inflamatorias (figura 1).

Sus efectos biológicos difieren de acuerdo a su concentración en el seno de cada tejido.

La ET1 es de vida media muy breve, a causa de la captura por su receptor, no por su degradación. Su concentración plasmática varía de 0,5 a $2,0 \mathrm{pg} / \mathrm{mL}$, la que no revela verdaderamente su actividad.

La ET1 está implicada, de modo importante, en el proceso de remodelamiento vascular y de regulación de la proliferación celular. Se trata, en efecto, de una sustancia mitogénica extraordinariamente potente, que produce hiperplasia e hipertrofia del músculo liso vascular $^{(10,11)}$.

\section{EL SISTEMA RENINA - ANGIOTENSINA - ALDOSTERONA (SRAA)}

Se trata de un sistema sumamente complejo, que comprende una serie de proteínas y 4 angiotensinas (I, II, III y IV) con actividades propias y específicas (figura 2).

El SRAA, además de sus acciones propiamente vasculares, induce estrés oxidativo a nivel tisular, el que produce tanto cambios estructurales como funcionales, especialmente disfunción endotelial, que configuran la patología hipertensiva (figura 3).

Las acciones de la angiotensina II incluyen: contracción del músculo liso vascular arterial y venoso, estimulación de la síntesis y secreción de aldosterona (¿por acción de la AIII?), liberación de noradrenalina en las terminaciones simpáticas, modulación del transporte del sodio $(\mathrm{Na})$ por las células tubulares renales, aumento del estrés oxidativo por activación de oxidasas NADH y NADPH

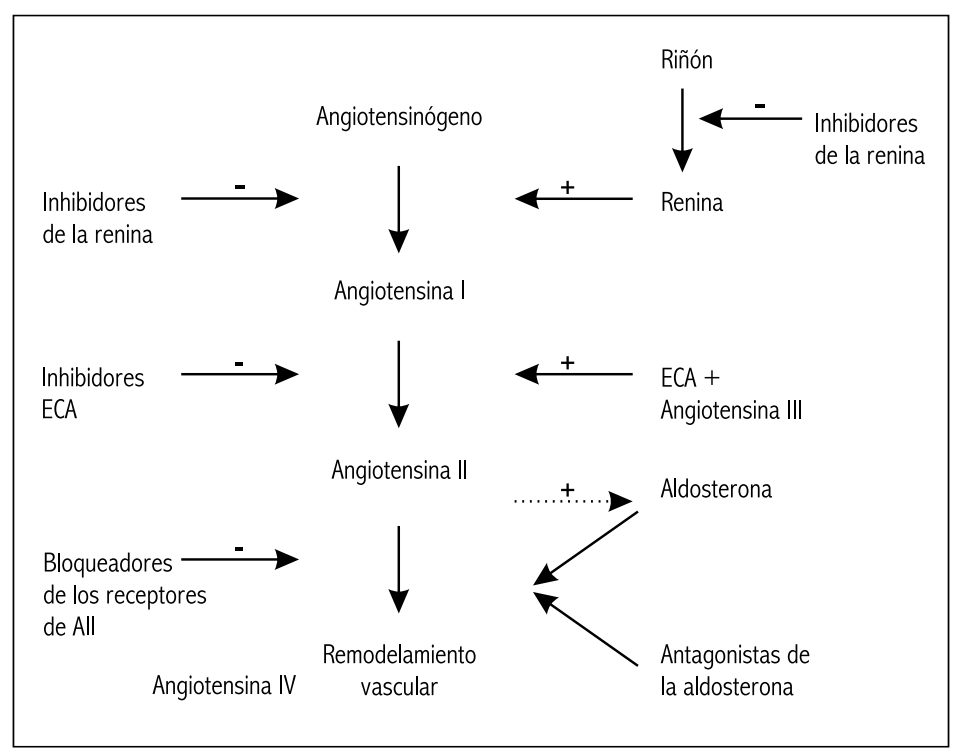

Figura 2. Sistema renina, angiotensina, aldosterona. dependientes, estimulación de la vasopresina/ADH, estimulación del centro dipsógeno en el sistema nervioso central, antagonismo del sistema del péptido atrial natriurético-natural (BNP) y tipo C (CNP)_(12), incremento de la producción de endotelina (ET1) y de prostaglandinas vasoconstrictoras (TXA2, PgF2 $\alpha$ ).

La AII y la aldosterona poseen, asimismo, acciones no hemodinámicas: aumento del VEGF con actividad proinflamatoria, estimulación de la producción de especies reactivas de oxígeno (ROS) nefrotóxicas, incremento de la proliferación celular y de la remodelación tisular, con aumento de la síntesis de citoquinas profibróticas y factores de crecimiento y reducción de la síntesis del $\mathrm{NO}$ y del $\mathrm{BNP}^{(12)}$.

Además, ambas (AII y aldosterona) incrementan el tejido colágeno a nivel cardiaco y vascular, por inhibición de la actividad de la metaloproteinasa (MMP1) que destruye el colágeno e incremento de los inhibidores tisulares específicos de la MMP1 (TIMPs). El resultado es el incremento del colágeno 3 en el corazón y vasos sanguíneos de los pacientes hipertensos. Estos efectos son mediados por el aumento de la expresión del factor de

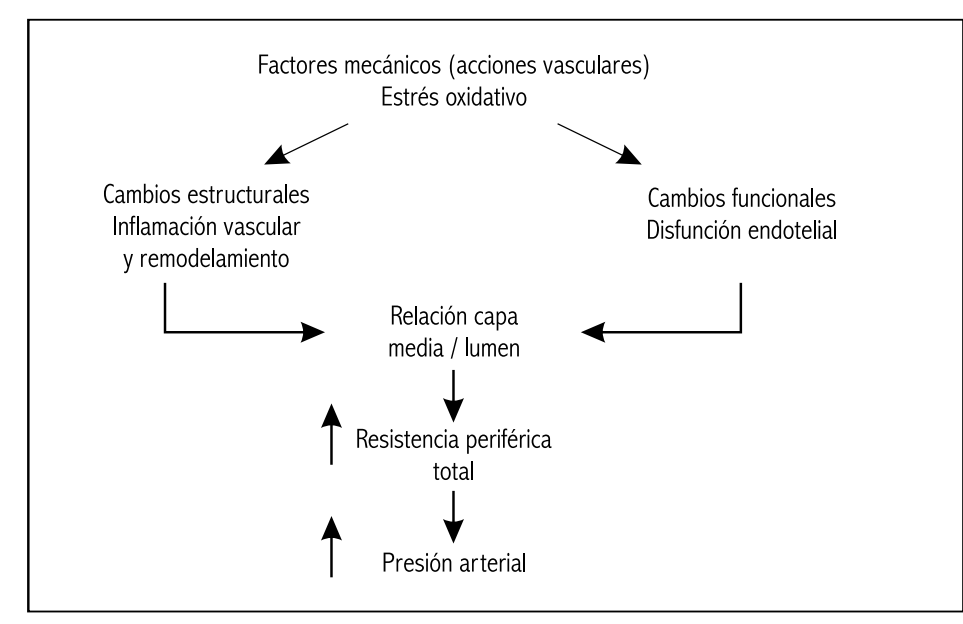

Figura 3. Factores mecánicos y acciones vasculares del sistema renina, angiotensina, aldosterona. 


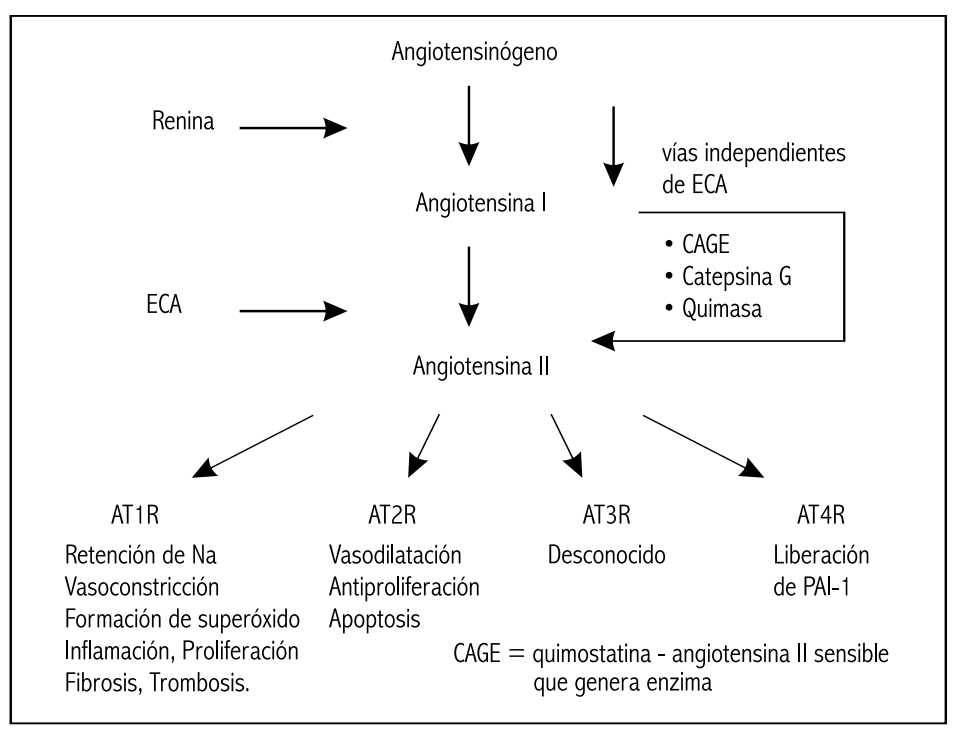

Figura 4. Receptores del sistema renina, angiotensina, aldosterona.

crecimiento de tumor TGF $\beta 1^{(13)}$. Finalmente, ambas sustancias poseen acción estimulante sobre el factor de crecimiento del tejido conectivo (CTGF) ${ }^{(13)}$.

Existen por lo menos 4 receptores de la AII, cada uno de ellos con características propias: AT1, AT2, AT3 y AT4 (figura 4).

En las tablas 1 y 2 se detalla los diversos efectos de la AII mediados por los receptores AT1 y AT2.

Se describe actualmente nuevas angiotensinas de acción vasodepresora, que provienen de la A1-7, que es una

Tabla 1. Efectos de la angiotensina II mediados por el receptor AT1.

- Vasoconstricción arterial y venosa

- Retención de $\mathrm{Na}$ (por la aldosterona)

- Hipertrofia de células vasculares y cardiacas

- Fibrosis vascular y cardiaca (acción sobre el colágeno)

- Hiperplasia de fibroblastos

- Citotoxicidad sobre el miocardio

- Aumento de endotelina (ET1)

- Aumento de vasopresina / ADH

- Facilitación simpato - adrenérgica

- Formación de RROs (superóxido)

- Aumento de PAl - 1

- Expresión genética alterada proteína esencialmente vasodilatadora y antiproliferativa. La A1-9 es de actividad intermedia entre la $\mathrm{A} 1$ y la A1-7. La A1-9 se convierte en A1-7 y nunca en A II ${ }^{(14)}$. La A1-9 se convierte en A1-7 por acción de una endopeptidasa tisular, la neprilisina, de alta concentración en el endotelio vascular. Una nueva angiotensina, la A1-12, posee también acción vasodepresora ${ }^{(15)}$.

Se ha descrito dos enzimas convertidoras de angiotensina (ECAs): la ECA1, que es la enzima fisiológica clásica, y la ECA2, que es la enzima que lleva a la formación de la A1-7, deprimida en algunos pacientes con $\mathrm{HTA}^{(14)}$.

El remodelamiento vascular, estimulado por el SRAA, es diferente en las arterias grandes y en las pequeñas. En el

Tabla 2. Efectos de la angiotensina II mediados por el receptor AT2.

- Antiproliferación

- Inhibición del crecimiento celular

- Diferenciación celular

- Reparación tisular

- Apoptosis

- Vasodilatación

- Desarrollo del riñón y tracto urinario (acción sobre tejidos fetales) primer caso, se trata de una remodelación hipertrófica; en el segundo, de una remodelación eutrófica (figura 5).

\section{EL FACTOR DIGITÁLICO ENDÓGENO (FDE)}

Factor ouabaíno-sensible. Se trata de un factor hormonal, descrito hace varios años, que inhibe a la bomba $\mathrm{Na}-\mathrm{K}-$ $\mathrm{Mg}$ - ATPasa ${ }^{(16)}$, con intensa actividad vasoconstrictora, de acción natriurética. Tiene un PM de 500-1000 D y es de probable origen hipotalámico. Su concentración se halla elevada en cerca de $50 \%$ de pacientes hipertensos esenciales ${ }^{(16)}$.

Su efecto natriurético se expresa de modo evidente e importante después de un aporte de sodio por vía oral (figura 6).

Resulta posible establecer un rol fisiopatológico en la HTA por incremento de la actividad plasmática del FDE, tal como se expresa en la figura 7 .

\section{HORMONAS \\ GASTROINTESTINALES}

DEL SISTEMA - Captación y

descarboxilación de los precursores de grupos amino (Amine precursor uptake descarboxilase - APUD)

Muchas de estas hormonas, secretadas por diversas células especializadas del aparato digestivo, poseen una intensa acción vascular. Así, p ej., el péptido intestinal vasoactivo (VIP) es intensamente vasodilatador, la coherina es vasoconstrictora, la colecistokinina (CCK) es vasodilatadora, la sustancia $P$ también es vasodilatadora. Lo mismo, la bombesina, las endorfinas y los eicosanoides ${ }^{(17)}$.

Existe la posibilidad de que estas hormonas contribuyan a la regulación de la presión arterial, regulación que se perdería en la HTA esencial.

Podría, entonces, existir una cierta asociación entre las patologías funcionales digestivas con la HTA.

Se especula acerca de la existencia de un eje hipotálamo-hipófiso-renosuprarrenal-intestinal de regulación de la presión arterial, que pudiera alterarse en algunos casos de HTA esencial ${ }^{(17)}$. 


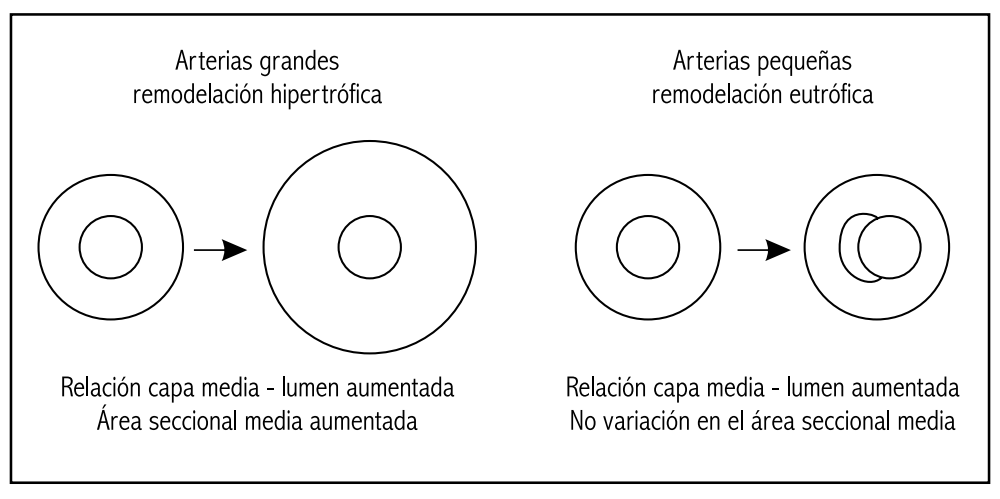

Figura 5. Remodelamiento vascular de las arterias grandes y pequeñas.

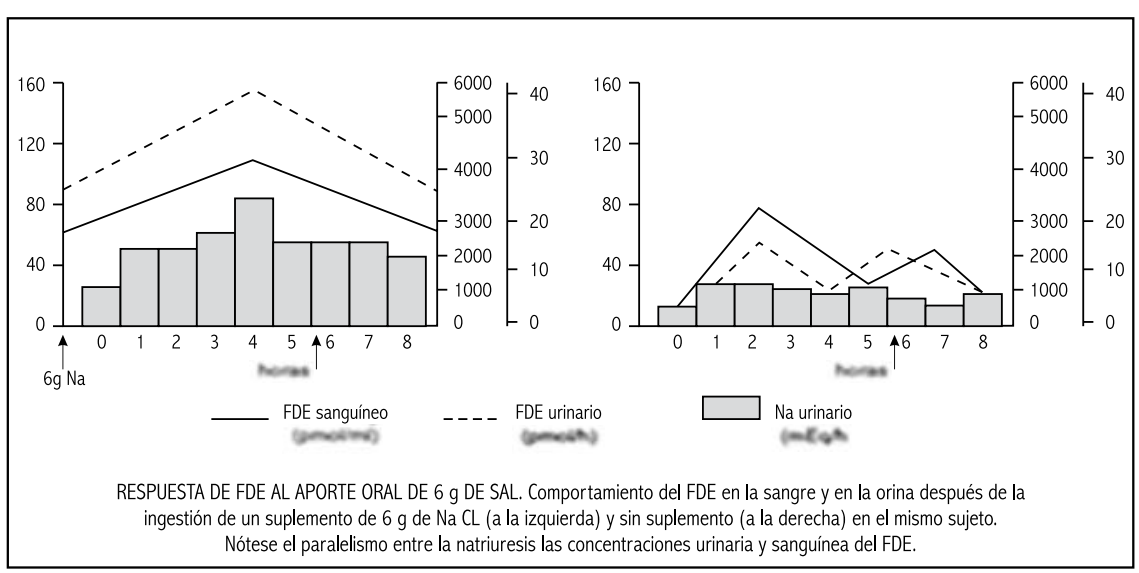

Figura 6. Factor digitálico endógeno: natriuresis.

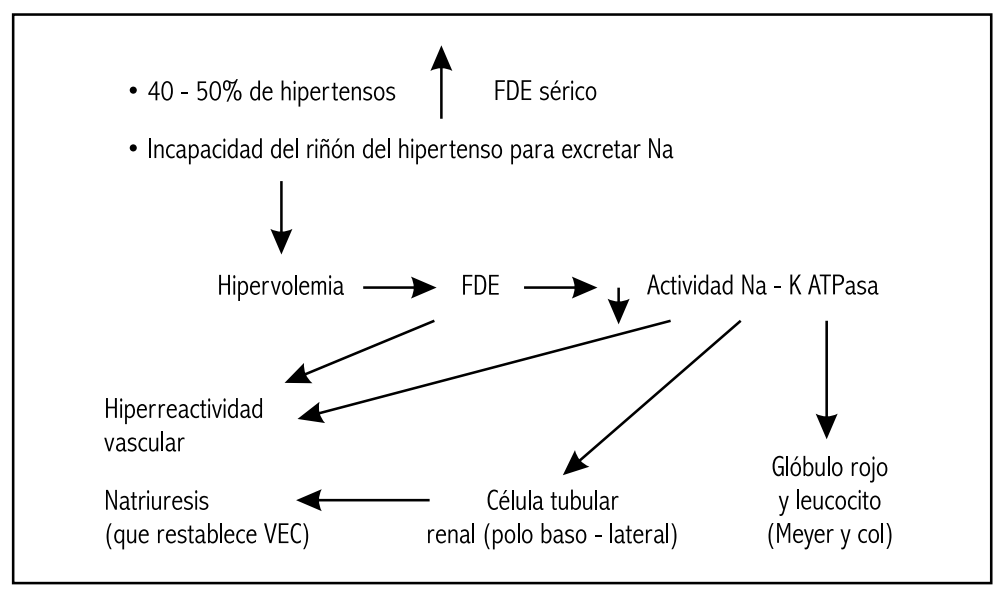

Figura 7. Factor digitálico endógeno e hipertensión arterial.

\section{Rol de la anemia en la HTA}

La hemoglobina es renoprotectora. La disminución de la hemoglobina promueve fibrosis intersticial renal, que puede llevar a una enfermedad renal crónica (ERC) hipertensiva.

Existe una probable estimulación del SRAA a la vía de las caspasas, que son enzimas proapoptóticas sobre las células eritropoyéticas y vasoconstrictoras, por un bloqueo de la PGI2 y el NO ${ }^{(18)}$.

\section{REFERENCIAS BIBLIOGRÁFICAS}

1. Hickey KA, Rubanyi G, Paul RJ, Highsmith RF. Characterization of a coronary vasoconstrictor produced by cultured endothelial cells. Am J Physiol. 1985;248(5 Pt 1):C550-6.

2. Yanagisawa M. Kurihara H, Kimura S, Tomobe Y, Kobayashi M, Mitsui Y, Yazaki Y, Goto K, Masaki T. A novel potent vasoconstrictor peptide produced by vascular endothelial cells. Nature. 1988;332(6163):411-5.

3. Inoue A, Yanagisawa M, KimuraS, Kasuya Y, Miyauchi T, Goto K, Masaki T. The human endothelin family: three structurally and pharmacologically distinct isopeptides predicted by three separate genes. Proc Natl Acad Sci USA. 1989;86(8):2863-7.

4. Arai H, Hori S, Aramori I, Ohkubo H, Nakanishi S. Cloning and expression of a CDNA encoding an endothelin receptor. Nature. 1990:348(6303):730-2.

5. Sakamoto A, Yanagisawa M, Sakurai T, Takuwa Y, Yanagisawa $\mathrm{H}$, Masaki T. Cloning and functional expression of human CDNA for the ETB endothelin receptor. Biochem Biophys Res Commun. 1991;178:656-63.

6. Schiffrin EL. Vascular endothelin in hypertension. Vascul Pharmacol. 2005;43:19-29.

7. Kotelevtsev Y, Webb DJ. Endothelin as a natriuretic hormone: the case for a paracrine action mediated by nitric oxide. Cardiovasc Res. 2001;51(3):481-8.

8. Dussaule JC, Boffa JJ, Tharaux PL, Fakhouri F, Ardaillou R, Chatziantoniou C. Endothelin, renal diseases and hypertension. Adv Nephrol Necker Hosp. 2000;30:281-303.

9. Fukuroda T, Fujikawat, Ozaki S, Ishikawa K, Yano M, Nishikibe M. Clearance of circulating endothelin-1 by ETB receptors in rats. Biochem Biophys Res Commun. 1994;199(3):1461-5.

10. Ozaki S, Ohwaki K, Ihara M, Fukuroda T, Ishikawa K, Yano M. ETB-mediated regulation of extracellular levels of endothelin-1 in cultured human endothelial cells. Biochem Biophys Res Commun. 1995;209(2):483-9.

11. Dupuis J, Stewart DJ, Cernacek P, Gosselin G. Human pulmonary circulation is an important 
site for both clearance and production of endothelin in the anesthetized dog. Circulation. 1996;94(7):1578-84.

12. Pagliaro P,Penna C. Rethinking the renin-angiotensin system and its role in cardiovascular regulation. Cardiovasc Drugs Ther. 2005;19(1):77-87.

13. Schmieder RE, Martus P, Klingbeil A. Reversal of left ventricular hypertrophy in essential hypertension. A meta-analysis of randomized double-blind studies. JAMA. 1996;275(19):1507-13.

14. Dzau VJ, Re T. Tissue angiotensin system in cardiovascular system. Basic Res Cardiol. 2008;93(suppl 2):7-14.
15. Jessup JA, Trask AJ, Chappell MC, Nagata S, Kato J, Kitamura K, Ferrario CM. Localization of the novel angiotensin peptide, angiotensin-(112), in heart and kidney of hypertensive and normotensive rats. Am J Physiol Heart Circ Physiol. 2008;294(6):H2614-H2618,

16. Wagner P. El factor digitálico endógeno. Hipertensión. 1996;2(3):111.

17. Wagner P. La anemia, consideraciones fisiopatológicas, clínicas y terapéuticas. Capítulo 7. $4^{\mathrm{a}}$ edición. 2008:160.

18. Kurella Tamura M, Xie D, Yaffe K, Cohen DL, Teal V, Kasner SE, Messé SR, Sehgal AR, Kusek J, Desalvo
KB, Cornish-Zirker D, Cohan J, Seliger SL, Chertow GM, Go AS. Vascular Risk Factors and Cognitive Impairment in Chronic Kidney Disease: The Chronic Renal Insufficiency Cohort (CRIC) Study. Clin J Am Soc Nephrol. 2010 0ct 28. [Publicación electrónica antes de la impresión].

Correspondencia:

Patrick Wagner-Grau

pwagner2310@yahoo.es 